American Journal of Applied Sciences 7 (5): 692-697, 2010

ISSN 1546-9239

(C) 2010Science Publications

\title{
Incorporating Workload and Performance Levels into Work Situation Analysis of Employees with Application to a Taiwanese Hotel Chain
}

\author{
${ }^{1}$ Tien-Hui Chen, ${ }^{1}$ Kun-Hsu Wu, ${ }^{1}$ Wei-Jen Lin, ${ }^{2}$ Wen-I Horna and ${ }^{3}$ Chich-Jen Shieh \\ ${ }^{1}$ Department of Tourism Management, \\ No.49, Jhonghua Rd., Hsin-Shih, Tainan County 744, Taiwan, ROC \\ ${ }^{2}$ Department of Leisure and Sports Management, Far-East University, \\ ${ }^{3}$ Department of International Business, Chang Jung Christian University (396), \\ Chang Jung Rd. Sec1, Kway Jen, Tainan County, Taiwan 71150, ROC
}

\begin{abstract}
Problem statement: Appropriate Human Resource Management (HRM) can motivate employees, develop their capabilities and enhance their productivity. However, before selecting the HRM practices to adopt, the workload levels of employees should be considered, since they may influence the success of such efforts. Approach: This study measured the relative workload of individual employees and incorporates the performance level into the work situation analysis. This analysis enables managers to be more aware of the work situations of employees and thus achieve better HRM decision making. Results: In addition, we presented an example application of the proposed analysis focusing on the reception clerks in a hotel chain and the results can aid management in deciding which HRM practices should be applied for specific employees so that their productivity can be improved. Conclusion: The advantage of this study is that it can provide a practical framework for managers to be more aware of the work situations of employees and thus achieve better HRM decision making.
\end{abstract}

Key words: Human resource management, workload, performance, hotel industry, reception clerk

\section{INTRODUCTION}

Appropriate Human Resource Management (HRM) can motivate employees, develop their capabilities and enhance their productivity. Morrison (1996) suggested that a firm's HRM practices could create an environment that elicits more customer-oriented behavior from employees. In turn, the behavior that these employees display will positively impact service quality. Therefore, efforts to promote service quality can focus on introducing appropriate HRM practices. However, employee workloads may influence the success of HRM practices. For example, if an employee has a heavy workload, meaning that they lack the ability to take on additional tasks, using incentives may not have a significant effect. Under this circumstance, the appropriate HRM practices should focus on training programs that develop the capabilities and productivity of employees.

A long-term heavy workload can affect an employee's physical or mental health, performance, or productivity. Consequently, heavy workloads have been shown to have a negative impact on turnover (Iverson and Pullman, 2000), certainly contribute to a state of stress and give rise to strain, accidents or illness. High employee turnover carries with it the problems of both a high labor cost and quality issues that hurt the performance and growth of a company (Davidson et al., 2006). Firth et al. (2004) thus suggested that managers should actively monitor the workloads of employees to reduce turnover. Therefore, this study measures the workloads and incorporates the performance level into the work situation analysis of individual employees to enable managers to be aware of the actual work conditions of staff, thus assisting in HRM decision making. Moreover, we focus the analysis in this work on the reception clerks in a hotel chain, with the aim of finding out what HRM practices should be applied for specific employees to motivate them, develop their capabilities and enhance their productivity.

Workload assessment: The techniques for measuring mental workload can be divided into three categories: performance-based measures, physiological measures and subjective ratings. However, in a complex task environment, performance measurement often cannot

Corresponding Author: Chich-Jen Shieh, Department of International Business, Chang Jung Christian University 396, Chang Jung Rd. Sec1, Kway Jen, Tainan County, Taiwan 71150, ROC 
indicate workload. The physiological measurement attempts to derive workload impact from factors such as heart-rate, respiration rate and blood pressure, though these may all be influenced by other factors (Veltman and Gaillard, 1996). Although physiological measures of workload are believed by some to be more accurate than subjective ones, subjective measures are widely applied to workload assessment. This is because the subjective approach is much easier to utilize, as employees are simply asked to assess their workloads using a rating-scales procedure and it is generally easy for staff to achieve this.

Subjective measures have been applied to evaluate two types of workloads using two different approaches. The first type focuses on assessing the workload for a specified task after it has been completed (Stedmon et al., 2007). The aims of this method are to improve operating characteristics and decrease the workload of an operator. The other type of workload assessment is designed to discriminate relative workloads within a group of employees in the same environment. Chang and Chen (2006) proposed a model to evaluate the relative workloads of employees and this is shown as follows:

$$
\begin{aligned}
\operatorname{Max} \mathrm{h}_{\mathrm{j}} & =\sum_{\mathrm{i}=1}^{\mathrm{s}} \mathrm{u}_{\mathrm{i}} \mathrm{y}_{\mathrm{ij}} \text { s.t. } \sum_{\mathrm{i}=1}^{\mathrm{s}} \mathrm{u}_{\mathrm{i}} \mathrm{y}_{\mathrm{ik}} \leq 1 \\
\mathrm{k} & =1,2, \ldots, \mathrm{nu}_{\mathrm{i}} \geq \varepsilon>0 \\
\mathrm{i} & =1,2, \ldots, \mathrm{s}
\end{aligned}
$$

Where:

$$
\begin{array}{ll}
\mathrm{h}_{\mathrm{j}} & =\text { The workload score of employee } \mathrm{j} \\
\mathrm{n} \text { and } \mathrm{s}= & \text { The number of employees and assessment } \\
& \text { factors, respectively } \\
\mathrm{y}_{\mathrm{ik}} & =\text { The level of factor } \mathrm{i} \text { of employee } \mathrm{k} \\
\mathrm{u}_{\mathrm{i}} & =\text { Gives the weight associated with factor } \\
\varepsilon & =\text { A positive non-Archimedean infinitesimal }
\end{array}
$$

The higher the $h_{j}$ score is the heavier the workload of employee $\mathrm{j}$. If $\mathrm{h}_{\mathrm{j}}$ is equal to one, then employee $\mathrm{j}$ is classified as having a relatively heavy workload and non-heavy workload otherwise. The advantage of this model is that it can discriminate the relative workloads of employees, despite the fact that most individuals will usually claim that theirs are heavy. In this study, we apply model (1) to the workload assessment of reception clerks in a hotel chain.

Human resource management: Human resource management is an organizational system that incorporates activities to mobilize and motivate people and to enable them to develop and reach fulfillment through their work, while at the same time contributing to organizational goals. HRM practices can effectively decrease the turnover rate (Cho et al., 2006) and are frequently acknowledged to play a central role in linking employee capabilities with the performance requirements of a company (Chen et al., 2003).

Motivation channels: Organizations influence employee motivation through a variety of channels, such as efforts to improve worker capability and through feedback or consequences related to worker performance (Franco et al., 2002). To develop employee capabilities and productivity, the literature notes that employee training is one of the critical HRM practices (Chen et al., 2003; Frayne and Geringer, 2000). At the individual level, training is a process that results in more effective job performance and is characterized by not only the acquisition of new skills, but also by the increased capacity to learn more and to recognize training opportunities (Amit and Belcourt, 1999). Employees with better learning abilities may actually hold more complex jobs or at least be predisposed to view the characteristics of their job more positively (Wright and Boswell, 2002). For feedback or consequences related to worker performance, a manager can use inducements like performance-related pay, promotions and extensive sharing of financial and training opportunities. In recent years, high performance organizations have become more inwardlooking in their creation of reward systems and they focus more on surveying their own workers concerning their performance and systems in order to motivate high performing employees (Hagan, 1996). Therefore, appropriate HRM practices are very important in retaining both the most able employees and in strengthening the capabilities of all the workforces.

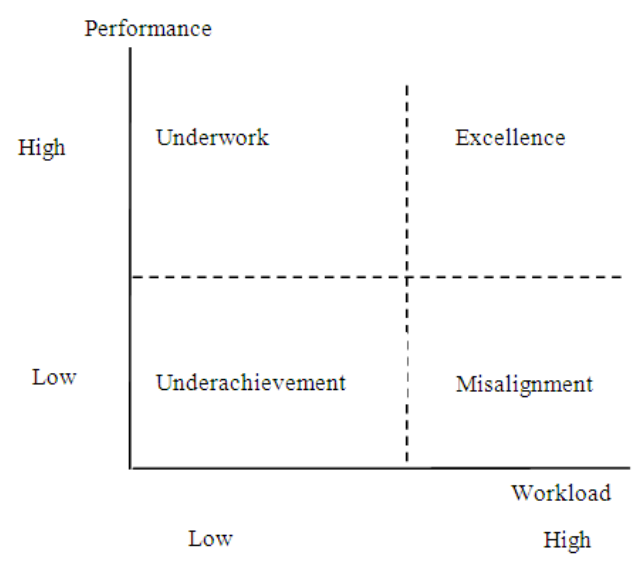

Fig. 1: Categories of employee situations 
Categories of work situations and available HRM practices: In order to ensure the effectiveness of HRM practices, managers should be aware of the work situation of employees. This study suggests plotting a scatter diagram of workload and performance levels by setting the $\mathrm{X}$ - and Y-axes as the workload and performance levels, respectively. The first quadrant can be separated into four portions presented as Fig. 1, namely underwork, underachievement, excellence and misalignment. Each point within one portion represents an employee's workload and performance situation.

When an employee has a relatively low workload but is a high performer, this study identifies the situation as underwork. When an individual has a low workload and is a low performer, this study identifies the situation as underachievement. When an employee has a high workload and is a high performer, this study describes the situation as excellence. When an individual has a high workload but is a low performer, this study describes the situation as misalignment. For each category of employees, a manager may apply different HRM practices to try to bring the individual up to a higher performance level.

The performance level of underworking employees maybe high, but their workload level is low. A low workload level can make an employee feel the lack of any challenge in their work and thus contribute to low job satisfaction. In this situation, employees may not feel valued or may feel that their worth is not recognized. Because such an employee has a greater unfilled workload capacity, additional tasks can be assigned and incentives can be developed that more completely engage them in their work. HRM practices should be focused on improving employee motivation to perform more tasks while maintaining a high achievement level.

For the underachieving employee, both performance and workload are low. In a competitive company, this type of employee is rare and if one exists, management should investigate the conditions that account for this. If the job is not suitable for the employee, the manager can consider reassignment, as a better job fit may improve performance. If a significant number of employee's exhibit poor performance and low workload characteristics, then HRM policies should be focused initially on system improvements, such as recruitment, selection, training and/or compensation programs.

Excellent employees, those who have both high workload and performance levels, are a company's most important human resource. In this environment, HRM practices may revolve around extra rewards and recognition, as well as greater autonomy, employment security and opportunities for promotion, in order to retain the high performers and to boost organizational performance. When employees have high security, receive feedback about their performance and have high autonomy in their work, they may experience feelings of satisfaction and hence have the intrinsic motivation to keep performing well. Nonetheless, managers should still pay attention to heavy workloads in such situations, for without a proper balance, they may create strain, accidents and illness.

Misaligned employees have high workloads, but they are low performers, indicating either that they do not have the abilities to do their tasks, or that their tasks are not suitable to their abilities. If this is the case, then managers can intensify their training programs and/or assign senior employees as instructors. If the characteristics of a task are not suitable for an employee, the manager can consider reassigning them to a new department where there is a more suitable job, thereby boosting their performance. At the same time, managers should further examine employee workloads to determine if there is a need to recruit more staff to balance workloads and improve individual performance.

After obtaining the workload and performance levels of employees, managers are able to make better decisions with regard to HRM practices and to mobilize their employees to execute organizational goals. Based on an analysis of workload and performance levels, managers are aware of the underlying work situation of each employee and can effectively apply appropriate HRM practices at the individual level. In the following case study we present an application of the proposed technique in a hotel chain, as well as the implications for the use of certain HRM practices.

\section{MATERIALS AND METHODS}

Human resources are one of the major resources of the hotel industry, since hospitality jobs require frequent customer contact. Such a work situation has been reported to be stressful for hospitality workers (Kim et al., 2007) and therefore contributes to the turnover intention. Indeed, the hotel industry has been characterized as having excessive employee turnover, which leads to higher costs due to the need to replace staff, as well as having detrimental effects on service quality (Stedmon et al., 2007). Because reception clerks are the first contract points for customers in a hotel, their service quality generates the first impression of the company. In other words, the service quality of a hotel depends heavily on the effectiveness with which frontline employees deal with customers and clients. Therefore, this study focuses on the reception clerks in a Taiwanese hotel chain. 
Am. J. Applied Sci., 7 (5): 692-697, 2010

Subject: Tourist hotels in Taiwan can be divided into two categories: international and ordinary and there were 64 and 31 of these, respectively, as of November, 2009. When the Asian Financial Crisis occurred in 1997, many hotels in Taiwan suffered due to a decline in the number of tourists. A new hotel chain, Toong-Mao Resorts and Hotels, was established after the crisis in 1997 by way of charter or commissioned responsibility and became the first reasonably priced recreational hotel chain in Taiwan. It has now become the second largest resort hotel chain in the country, its service performance has won various national awards and it is one of the best regarded tourism brands in Taiwan.

Assessment factors: To investigate the workload and performance levels of the reception clerks in ToongMao hotels, the NASA Task Load Index (NASA-TLX), a widely used technique for subjective workload assessment, is utilized. NASA-TLX is a multidimensional approach to measure workload by a weighted workload score and contains six factors: mental demands, physical demands, temporal demands, effort, frustration level and performance.

In this study, we use the factors of the NASA-TLX as the workload assessment factors in Model (1) and individuals subjectively rate their workload on five factors, using a rating scale from 0-100. The five factors are mental demands, $Y_{1}$, physical demands, $Y_{2}$, temporal demands, $Y_{3}$, effort, $Y_{4}$ and frustration level, $Y_{5}$. The performance level, $Y_{6}$, is obtained from the routine performance appraisal of the enterprise and the scale is from $0-100$.

In rating the workload factors, each reception clerk considered their own perceived workload and then rated each question. This implies that the rating result contains the capacity of the individual. For example, one question for the frustration level factor is: How insecure, discouraged, irritated, stressed and annoyed versus secure, gratified, content, relaxed and complacent do you feel in your job? When individuals rate this question, their perceived loading contains their capacity. In this study, the rating scale is from 0 to 100 for each factor. In other words, we assume the capacity of each individual is 100 , although the maximum tolerance of each employee is different. The perceived workload is an index of an individual on a specific factor.

\section{RESULTS}

In this study, twenty-three Toong-Mao hotel chain reception clerks are evaluated and the data obtained for each factor are presented in Table 1. LINGO software
Table 1: Levels of factors and workload scores for individual employees

\begin{tabular}{|c|c|c|c|c|c|c|c|}
\hline \multirow{2}{*}{$\begin{array}{l}\text { Employee } \\
\text { No. }\end{array}$} & \multicolumn{6}{|c|}{ Volume of factor } & \multirow[b]{2}{*}{$\begin{array}{l}\text { Workload } \\
\text { score }\end{array}$} \\
\hline & $\mathrm{Y}_{1}$ & $\mathrm{Y}_{2}$ & $\mathrm{Y}_{3}$ & $\mathrm{Y}_{4}$ & $\mathrm{Y}_{5}$ & $\mathrm{Y}_{6}$ & \\
\hline 1 & 87 & 80 & 80 & 85 & 70 & 90 & 0.916 \\
\hline 2 & 70 & 70 & 90 & 70 & 50 & 82 & 0.947 \\
\hline 3 & 82 & 78 & 88 & 80 & 50 & 85 & 0.926 \\
\hline 4 & 85 & 80 & 85 & 80 & 65 & 80 & 0.895 \\
\hline 5 & 88 & 80 & 85 & 85 & 80 & 85 & 0.926 \\
\hline 6 & 72 & 65 & 70 & 75 & 60 & 72 & 0.790 \\
\hline 7 & 85 & 70 & 86 & 83 & 50 & 80 & 0.905 \\
\hline 8 & 60 & 60 & 70 & 60 & 60 & 88 & 0.737 \\
\hline 9 & 95 & 70 & 90 & 95 & 65 & 90 & 1.000 \\
\hline 10 & 90 & 85 & 90 & 95 & 85 & 85 & 1.000 \\
\hline 11 & 70 & 70 & 84 & 83 & 50 & 82 & 0.884 \\
\hline 12 & 75 & 60 & 87 & 80 & 70 & 83 & 0.916 \\
\hline 13 & 80 & 90 & 90 & 80 & 82 & 83 & 1.000 \\
\hline 14 & 78 & 70 & 85 & 75 & 60 & 90 & 0.895 \\
\hline 15 & 80 & 65 & 90 & 80 & 50 & 80 & 0.947 \\
\hline 16 & 80 & 78 & 80 & 90 & 65 & 85 & 0.947 \\
\hline 17 & 80 & 90 & 95 & 80 & 88 & 70 & 1.000 \\
\hline 18 & 82 & 75 & 83 & 77 & 50 & 85 & 0.874 \\
\hline 19 & 60 & 80 & 70 & 87 & 80 & 80 & 0.916 \\
\hline 20 & 70 & 80 & 80 & 50 & 70 & 80 & 0.889 \\
\hline 21 & 95 & 90 & 95 & 95 & 90 & 65 & 1.000 \\
\hline 22 & 80 & 80 & 95 & 80 & 78 & 80 & 1.000 \\
\hline 23 & 90 & 88 & 90 & 90 & 80 & 85 & 0.978 \\
\hline
\end{tabular}

was utilized to run Model (1) and the results, showing the workload score of each employee by using five factors are presented in the last column of Table 1, since these factors are rated by themselves. The workload scores indicate that employees 9, 10, 13, 17, 21 and 22 have a relatively heavy workload among these twentythree reception clerks, since their scores are equal to one. In contrast, the other reception clerks are considered to have relatively non-heavy workloads, as their scores are less than one.

\section{DISCUSSION}

In this study, five workload assessing factors were rated by the reception clerks themselves and the performance factor was obtained from the performance appraisal of the enterprise. Therefore, the workload score and the performance level of each reception clerk are statistically independent. We plot the scatter diagram of the workload scores and the performance levels by setting the $\mathrm{X}$-axis as the workload level and the Y-axis as the performance level in Fig. 2. This study subjectively separates these observations by drawing a vertical line at the position of the workload score equal to 0.82 and a horizontal line at the position of the performance level of 75 . Then, the first quadrant is separated into four portions.

According to the classifications in Fig. 2, employees 6, 8, 17 and 21 are far from the constellations. 
Am. J. Applied Sci., 7 (5): 692-697, 2010

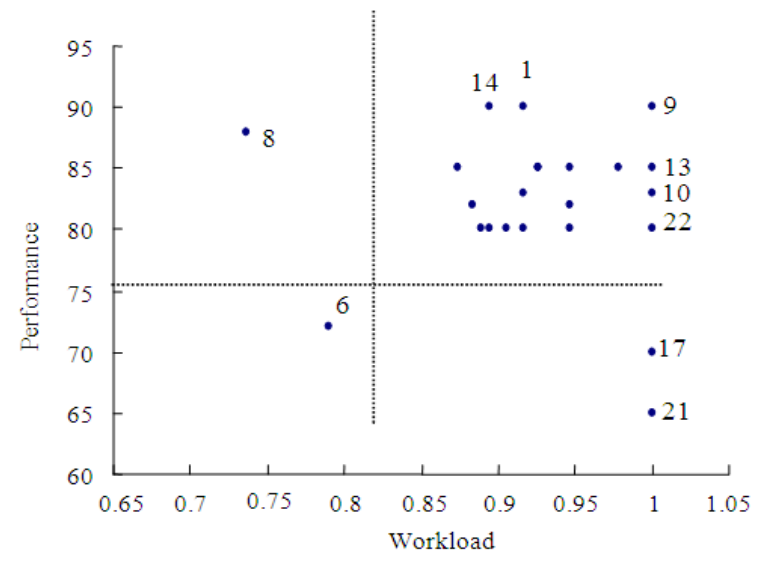

Fig. 2: Work situation for all reception clerks

Employee 8 is located at the far left, on the decreasing workload score axis, meaning that they belong to the underwork category. In other words, employee 8 has more available capacity to do additional tasks. This study suggests that the manager might assign additional tasks to employee 8 and use incentives to motivate them to undertake these in a productive fashion. Moreover, a leadership training program should also be offered.

Employees 17 and 21 have relatively heavy workloads, but their performance levels are the lowest among all reception clerks. These two employees thus belong to the misalignment category. This study further examines the load values of each factor rated by these two reception clerks themselves. In Table 1 , it is noted that employees 17 and 21 have the highest two values for the frustration level, meaning that they have heavy workloads, poor performance and a high frustration level in their job. The interpretation is that these two employees may not have the ability to do their tasks, or that their tasks are not suitable for them. This study thus suggests that management should offer intensive training programs and assign two senior employees as their instructors.

Employee 6 belongs to the underachieving category, since their performance and workload levels are lower than those of most employees. The lower workload level indicates that the gap between task demands and the capacity of employee 6 is larger than that for the other reception clerks. Since a lower workload is associated with poor performance, it is possible that the job is not suitable for employee 6 , or that they are bored with their work. The manager can thus consider reassignment to a new position where there is a better job fit, or use incentives to motivate employee 6 and to improve their performance.
However, it should be noted that most of the reception clerks belong to the excellent category. This may be the reason why Toong-Mao has won various national awards and has become one of the best tourism brands in Taiwan. For the heavy workload individuals in this category, namely employees 9, 10, 13 and 22, management should pay more attention to balancing their workloads, by reassigning tasks. However, for the relatively non-heavy workload reception clerks, management can offer training programs in a fixed time period to elicit more customer-oriented behavior.

Six months after the original survey, employee 8 had been promoted to the director of a team with seven members and employees 10, 13, 17 and 21 had left the hotel chain. It should be noted that four of the six heavy workload employees left work voluntarily, implying that a heavy workload may influence turnover in the Toong-Mao hotel chain. For the other employees, the management indicated that their performance had improved slightly after workloads had been balanced and that the atmosphere of the work environment had improved greatly.

\section{CONCLUSION}

The importance of service quality to business competitiveness has been established in a broad business context. It is generally accepted that service quality is antecedent to customer satisfaction and that customer satisfaction is antecedent to customer loyalty. Perceived service quality derives from the individual service encounter between the customer and the service provider, during which the customer evaluates the service offered and develops satisfaction or dissatisfaction. An enterprise with better performance and a higher level of service quality can constantly capture competitive advantages in the service sector. In other words, when employees have demonstrated excellent service behavior, the customer perception of service quality has increased. Because a company's HRM practices can create an environment that elicits more customer-oriented behavior from employees, it is an important issue for managers to adopt appropriate ones. However, before doing so, the manager should be aware of the work situation of each employee, since the different workloads of individuals may influence the success of implementing these HRM practices.

Human resources are one of a company's most important assets and the ability to attract and retain talent is rapidly becoming one of the core competences of high performance organizations. This article offers a work situation analysis by plotting a scatter diagram of workload and performance levels for employees. 
Although one cannot classify individuals only according to workload and performance levels, this analysis can raise decision maker awareness of the work situations of employees and thus aid in their decisions about which HRM practices to adopt. Because workload measurement is usually multidimensional, it is worth identifying the critical factors that the decision maker should focus on in order to effectively alleviate the workloads of heavy workload employees. Consequently, in future work, researchers can identify the critical factors to better determine the priorities of dimensions for workload improvement. To this end, we demonstrate a framework for workload assessment, as well as give an example analysis focusing on the reception clerks in a hotel chain. The results of this study are expected to be helpful to the managers of hospitality companies in planning and executing HRM practices.

\section{REFERENCES}

Amit, R. and M. Belcourt, 1999. Human resources management processes: A value-creating source of competitive advantage. Eur. Manage. J., 17: 174-781. DOI: 10.1016/S0263-2373(98)00076-0

Chang, S.Y. and T.H. Chen, 2006. Discriminating relative workload level by data envelopment analysis. Int. J. Ind. Ergonom., 36: 773-778. DOI: 10.1016/j.ergon.2006.06.003

Chen, L.H., S.Y. Liaw and T.Z. Lee, 2003. Using an HRM pattern approach to examine the productivity of manufacturing firm-An empirical study. Int. J. Manpower, 24: 299-318. DOI: 10.1108/01437720310479750

Cho, S., R.H. Woods, S.C.S. Jang and M. Erdem, 2006. Measuring the impact of human resource management practices on hospitality firms' performances. Int. J. Hosp. Manage., 25: 262-277. DOI: 10.1016/j.ijhm.2005.04.001

Davidson, M., C. Guilding and N. Timo, 2006. Employment, flexibility and labor market practices of domestic and MNC chain luxury hotels in Australia: Where has accountability gone? Int. J. Hosp. Manage., 25: 193-210. DOI: 10.1016/j.ijhm.2005.08.001
Firth, L., D.J. Mellor, K.A. Moore and C. Loquet, 2004. How can managers reduce employee intention to quit? J. Manage. Psychol., 19: 170-187. DOI: 10.1108/02683940410526127

Franco, L.M., S. Bennett and R. Kanfer, 2002. Health sector reform and public sector health worker motivation: A conceptual framework. Soc. Sci. Med., 54: 1255-1266. DOI: 10.1016/S02779536(01)00094-6

Frayne, C.A. and J.M. Geringer, 2000. Selfmanagement training for improving job performance: A field experiment involving salespeople. J. Applied Psychol., 85: 361-372. DOI: 10.1037/0021-9010.85.3.361

Hagan, C.M., 1996. The core competence organization: Implication for human resource practices. Hum. Res. Manage. Rev., 6: 147-164. DOI: 10.1016/S1053-4822(96)90017-0

Iverson, R.D. and J.A. Pullman, 2000. Determinants of voluntary turnover and layoffs in an environment of repeated downsizing following a merger: An event history analysis. J. Manage., 26: 977-1003. DOI: $10.1177 / 014920630002600510$

Kim, H.J., K.H. Shin and W.T. Umbreit, 2007. Hotel job burnout: The role of personality characteristics. Int. J. Hosp. Manage., 26: 421-434. DOI: 10.1016/j.ijhm.2006.03.006

Morrison, E.W., 1996. Organizational citizenship behavior as a critical link between HRM practices and service quality. Hum. Res. Manage., 35: 493512. DOI: $10.1002 /(\mathrm{SICI}) 1099-050 \mathrm{X}$

Stedmon, A.W., S. Sharples, R. Littlewood, G. Cox and H. Patel et al., 2007. Datalink in air traffic management: Human factors issue in communications. Applied Ergon., 38: 473-480. DOI: 10.1016/j.apergo.2007.01.013

Veltman, J.A. and A.W.K. Gaillard, 1996. Physiological indices of workload in a simulated flight task. Biol. Psychol., 42: 323-342. DOI: 10.1016/03010511(95)05165-1

Wright, P.M. and W.R. Boswell, 2002. Desegregating HRM: A review and synthesis of micro and macro human resource management research. J. Manage., 28: 247-276. DOI: 10.1177/014920630202800302 